\title{
DISPERSAL AND SOCIAL ATTRACTION AFFECT COLONY SELECTION AND DYNAMICS OF LESSER KESTRELS
}

\author{
David Serrano, ${ }^{1,3}$ Manuela G. Forero, ${ }^{2}$ José A. Donázar, ${ }^{1}$ and José L. Tella ${ }^{1}$ \\ ${ }^{1}$ Estación Biológica de Doñana, Consejo Superior de Investigaciones Científicas, Department of Applied Biology, Avda. \\ María Luisa s/n, Pabellón del Perú, 41013 Sevilla, Spain \\ ${ }^{2}$ Instituto Mediterráneo de Estudios Avanzados, Consejo Superior de Investigaciones Científicas-Universidad de las Islas \\ Baleares, Department of Natural Resources, Population Ecology Group, c/ Miquel Marques, 21, \\ 07190 Esporles, Mallorca, Spain
}

\begin{abstract}
We studied the mechanisms that regulate colony dynamics in a Spanish population of Lesser Kestrels, using eight years of data from banded individuals in 494 colony-years. Colony growth was positively related to breeding success at the colony the year before. However, individuals of all dispersal statuses, i.e., adult and first-breeding philopatric and immigrant birds, significantly contributed to changes in colony size, indicating an important effect of dispersal on colony dynamics via colony quality. Given that there is strong evidence that Lesser Kestrels base their settlement decisions on conspecifics, we tested whether immigrants used the number of previously settled residents in year $t$ (social or conspecific attraction hypothesis) and/or the breeding performance of conspecifics in year $t-1$ (performance-based attraction hypothesis) to select their breeding colony. Breeding success of colonies varied both in space and time and was autocorrelated from one year to the next. Moreover, lifetime reproductive success of Lesser Kestrels was positively associated with colony size, and individuals can predict final colony size early in the breeding season, so assumptions of both hypotheses were fulfilled. Our results support the social attraction hypothesis, since immigration was positively related to the number of philopatric adults, but not to conspecific breeding success the year before. Given that departure decisions of adults were based on personal information about breeding success and colony size is related to fitness prospects, previously settled individuals provide easy and reliable information about colony quality, and social attraction could be seen as a particular case of public information in Lesser Kestrels. Consistently, absolute numbers of both philopatric adults and immigrants increased with colony size the year before, although immigrants increased only up to a threshold beyond which this trend disappeared. Therefore, immigrants seem to be prevented from settling in the largest colonies, which could explain why all individuals do not concentrate in a few big colonies, but some settle in suboptimal colonies or colonize unoccupied sites. This opposing effect of conspecifics, together with the low levels of temporal autocorrelation in colony quality between time lags $\geq 2 \mathrm{yr}$, could promote colony size variability and facultative coloniality in this species.
\end{abstract}

Key words: colony dynamics; colony quality; conspecific attraction; dispersal; Falco naumanni; habitat copying; Lesser Kestrel; performance-based attraction; predation; public information; Spain.

\section{INTRODUCTION}

Much consideration and debate have been focused on ecological processes and evolutionary forces driving coloniality (e.g., Alexander 1974, Wittenberger and Hunt 1985, Kharitonov and Siegel-Causey 1990, Brown and Brown 1996, 2001, Rolland et al. 1998), but factors affecting colony size and dynamics in vertebrates remain poorly understood. Apart from physical restrictions in the availability of nesting substrate (e.g., Potts et al. 1980, Forbes et al. 2000), colony populations may be regulated by factors affecting fitness components such as food availability (Furness and Birkhead 1984, Forero et al. 2002, Oro et al. 2003), pre-

\footnotetext{
${ }^{3}$ E-mail: serrano@ebd.csic.es
}

dation pressure (Southern et al. 1985, Kilpi 1995), and parasite loads (Duffy 1983, Brown and Brown 1986). If colonies operate as closed populations, colony dynamics might be explained by changes in these endogenous fitness components. However, colonies, as other subdivided populations, can be more accurately visualized as open systems connected by dispersal of individuals among them (Nur and Sydeman 1999), so settlement and departure decisions can greatly influence their dynamics (Clobert et al. 2001, Oro et al. 2003). However, the question of how the abovementioned limiting factors affect dispersal and settlement of individuals to regulate colony size have received remarkably little attention.

A central theme for a better understanding of population and colony dynamics is to know the cues that individuals use to choose a settlement site (Reed et al. 
1999). Assuming that individuals gather information about habitat quality (Cody 1985, Stamps 2001), two main types of strategies could be used: (1) strategies using information about environmental factors and (2) strategies using information on conspecifics (see references in Doligez et al. [2003]). To the extent that conspecifics may provide reliable information about intrinsic habitat quality, strategies based on conspecific cues are more parsimonious than direct habitat assessment and are one of the most important connections between habitat selection theory and population dynamics (Danchin and Wagner 1997). Both experimental and correlative data from a wide range of taxa have provided strong evidence that individuals may cue on the presence and abundance of conspecifics to select where to settle ("social or conspecific attraction hypothesis"; e.g., Stamps 1988, Hoeck 1989, Booth 1992, Pawlik 1992, Muller et al. 1997, Muller 1998, Etterson 2003, Ward and Schlossberg 2004). This mechanism is expected to operate broadly in breeding habitat patch choice of social animals such as colonial birds (Shields et al. 1988, Forbes and Kaiser 1994, Sarrazin et al. 1996, Serrano and Tella 2003, Serrano et al. 2003). In fact, the use of decoys and taped vocalizations have been used successfully in seabirds to attract individuals and create new colonies in previously vacant areas (e.g., Kotliar and Burguer 1984, Kress and Nettleship 1988, Podolsky 1990, Jeffries and Brunton 2001). Recently, it was suggested that individuals could use the local reproductive success of conspecifics in the past as an index of patch quality ("performance-based attraction hypothesis," Danchin and Wagner 1997). The role of this kind of "public information" (i.e., information derived from the performance of conspecifics; Valone 1989, Danchin et al. 2001, Valone and Templeton 2002) in habitat selection has been demonstrated both for territorial (Doligez et al. 2002) and colonial species (Danchin et al. 1998, Brown et al. 2000, Boulinier et al. 2002), but has been rarely tested simultaneously with the social attraction hypothesis (Doligez et al. 2004).

The aim of this study is to identify the processes that regulate colony dynamics, i.e., changes in the number of breeding pairs between consecutive years, within a long-monitored population of the facultatively colonial Lesser Kestrel (Falco naumanni). We first investigated if colony dynamics was affected by breeding success and colony size the previous year. Secondly, we determined the relative importance of philopatry and immigration on colony dynamics. This was possible because most individuals in our population were banded, and thereby we could determine the origin and dispersal status of individuals contributing to changes in colony size. In Lesser Kestrels, there is strong evidence that individuals rely on conspecifics cues to decide where to settle. Most individuals settle in previously occupied colonies (Serrano et al. 2003) in spite of $\sim 90 \%$ of suitable unoccupied sites mixed with colonies in our population (Serrano et al. 2001b). Furthermore, dispersal patterns are strongly affected by the spatial distribution and size of neighboring colonies and subpopulations (Serrano et al. 2001a, 2003, Serrano and Tella 2003). Therefore, we investigated the predictions of both the social and the performance-based attraction hypotheses. These hypotheses required the fulfillment of some general assumptions. An obvious assumption for the evolution of breeding site selection is that the quality of the environment must be patchy (Orians and Wittenberger 1991). Moreover, to have evolved as an adaptive strategy, any social cue used to select breeding site should reliably reflect this variation in site suitability. In this way, if social attraction is operating, two key assumptions should be met: (1) colony size must be positively related to fitness prospects of individuals and (2) incoming individuals should be able to estimate final colony size early in the breeding season due to nonsynchronic settlement of individuals in the colonies. The first assumption was previously tested and fulfilled in Lesser Kestrels, as lifetime reproductive success is positively correlated with colony size (Tella 1996). On the other hand, a fundamental assumption for the use of public information is that patch quality must be autocorrelated between years (Danchin et al. 1998, Brown et al. 2000). Only in this way may prospectors benefit by the information acquired in previous breeding seasons to select their breeding patch.

The social attraction hypothesis predicts that settlement decisions are based on the presence and number of conspecifics (Stamps 1988, Reed and Dobson 1993, Serrano et al. 2001a, Stamps 2001). Given that the first individuals settling in the colonies early in the breeding season were the experienced philopatric adults, we predicted that the number of immigrants at a colony should increase with adult philopatry. The performance-based attraction hypothesis predicts that the net recruitment of individuals at a colony should be positively correlated with its reproductive success in the previous breeding season (Boulinier and Danchin 1997, Danchin and Wagner 1997), so the number of nonlocal recruits that had the opportunity to prospect should be positively correlated with the mean breeding success the previous year.

\section{Methods \\ Study area and study species}

Lesser Kestrels were studied from 1993 to 2000 in an area of $\sim 10000 \mathrm{~km}^{2}$ situated on the Mid Ebro Valley, northeastern Spain. As in most of the European populations, kestrels breed here in buildings, primarily under tiled roofs of abandoned farmhouses surrounded by extensive cultivations of cereals (Tella et al. 1998a). Buildings were occupied by both solitary pairs and colonies of 2-43 pairs. Thus, Lesser Kestrels form colonies of a similar size to those found in natural sites (Tella et al. 2004), suggesting that the social environ- 
ment has not changed by the occupation of buildings. Lesser Kestrels are long-distance migratory birds; firstarriving individuals settle in the colonies in late February and leave them in August, although a small part of the population is sedentary (Tella and Forero 2000). Males choose a nest hole and defend vigorously a small area around it while displaying to attract females. Once established, the female also defends the nest hole. Firstyear birds typically arrive later than adults from the wintering quarters, and individuals breed for the first time in their first or second year of life.

Shortage of suitable nesting sites does not explain variations in colony size in this population (Tella 1996). Most suitable buildings remain unoccupied (Serrano et al. 2001b), nest site availability being limited only in a few colonies (Forero et al. 1996). In fact, availability of nesting sites does not correlate with colony size (D. Serrano and J. L. Tella, unpublished data). Dispersal patterns of Lesser Kestrels are well known in this population. Most individuals disperse from their natal colony, although they tend to be philopatric at a local scale by dispersing a median distance of $7225 \mathrm{~m}$ (Serrano and Tella 2003, Serrano et al. 2003). Once settled, individuals show low but significant rates of breeding dispersal (27\%), dispersing usually to colonies situated in their previous year home range (Serrano et al. 2001a).

\section{Field procedures}

Since 1993, Lesser Kestrels were individually marked with a numbered metal ring and a plastic color band engraved with an alphanumeric code that can be read with spotting scopes. We banded 4901 fledglings and 640 adults that were captured at the nests. Each year, a census of the number of breeding pairs in each colony was conducted from early May to June by counting all established pairs defending a nest site. Colony size was defined as the final number of established pairs. From early June, nearly all nests were checked to record breeding success, which was estimated as the number of nestlings older than $21 \mathrm{~d}$. Causes of breeding failure were inferred by visual inspection of nest remains. Evidence such as blood, feathers, removed tiles, or predator tracks revealed predation, while dead chicks underweighted for their age revealed starvation. Red foxes (Vulpes vulpes) and brown rats (Rattus rattus) were the main causes of total breeding failure. For a more detailed description of the field procedures, see Serrano et al. $(2001 a, 2003)$ and Serrano and Tella (2003).

\section{Measurement of colony dynamics}

Changes in colony size were defined as $r=\ln \left(N_{t}+\right.$ 1) $-\ln \left(N_{t-1}+1\right)$, where $N_{t}$ and $N_{t-1}$ were pair counts at a colony in year $t$ and $t-1$, respectively. In our population, some colonies have increased dramatically and others have decreased or even have gone extinct, so our definition includes both increasing and decreas- ing colonies. We considered all colonies occupied in year $t-1$, excluding from the analyses colonies occupied in year $t$ but unoccupied in year $t-1$ (i.e., colonizations). Twenty-six colonies in which colony growth could have been limited by nest site availability were also removed from the data set. Thus, our final sample included data from 494 colony-years (range 47132 colonies per year) having unoccupied holes in both year $t-1$ and $t$.

\section{Dispersal status of individuals contributing to colony dynamics}

Colony dynamics depends on the balance between the negative effects of mortality and emigration and the positive effects of natal philopatry and immigration. To analyze the relative importance of these factors, we computed the number of individuals of each dispersal status (i.e., philopatric adults, philopatric first-breeding birds, immigrating adults, and immigrating first-breeding birds) for each colony-year. As can be noted, number of philopatric birds takes into account both losses by mortality and emigration. For analyses, we considered only those colonies in which more than $50 \%$ of breeding individuals were identified (median $=86 \% ;$ range $51-100 \%, N=210$ colonies $)$. As we do not expect any kind of bias in the dispersal composition of banded and nonbanded individuals at each colony, we assumed that the sample of banded individuals reflects accurately the real proportion of individuals of each dispersal status in the selected colonies. For each colony-year, we divided the number of identified birds of each dispersal status by the total proportion of individuals identified, to obtain standardized estimates of the dispersal composition of the colonies.

Our results could be affected by spatial biases in the distribution of the colonies. For example, as large colonies produce more young (Tella 1996), immigration patterns in the largest colonies could be trivially explained by natal philopatry if these colonies were clumped in space. We examined the number of large (i.e., $\geq 10$ breeding pairs) and small ( $<10$ breeding pairs) colonies within a radius of $7225 \mathrm{~m}$ (median natal dispersal distance; Serrano et al. 2003) around each large colony and found that the number of small colonies was higher than the number of large ones in all years of study (median values per year; 1994, 21 small vs. 3 large; 1995, 7 vs. 1; 1996, 4 vs. 1; 1997, 12 vs. 1 ; 1998 , 11 vs. 2 ; 1999 , 16 vs. 1 ; 2000, 13 vs. 1$)$. Individuals had therefore a wide range of dispersal options in terms of colony size.

\section{Predictability of colony size}

To investigate whether Lesser Kestrels returning from the wintering quarters can predict final colony size in advance, we censused 26 colonies representative of all colony sizes in 1994 from the arrival of the first individuals in late February to the mean date of egg- 
TABLE 1. Mixed model for the effect of average breeding success and colony size on colony dynamics of Lesser Kestrels in the Mid Ebro Valley, northeastern Spain.

\begin{tabular}{lccrr}
\hline \hline \multicolumn{1}{c}{ Parameter } & Parameter estimate & SE & $F$ & \multicolumn{1}{c}{$P$} \\
\hline Intercept & -0.3279 & 0.05195 & & \\
Breeding success (BS) & 0.1611 & 0.01853 & 75.58 & $<0.0001$ \\
Colony size (CS) & -0.02423 & 0.007327 & 10.94 & 0.0011 \\
BS $\times$ CS & 0.009144 & 0.003340 & 7.49 & 0.0066 \\
Numerator df & 1 & & & \\
Denominator df & 246 & & & \\
Explained deviance (\%) & 34.09 & & & \\
\hline
\end{tabular}

Notes: All variables were measured in year $t-1$. Colony site and year were fitted as random terms. Note that breeding success and colony size are weakly, although significantly, intercorrelated (Spearman rank correlation coefficient, $r_{\mathrm{s}}=0.248, P<0.0001$ ).

laying in mid-May. Censuses were performed every nine days by counting the maximum number of birds present at each colony during five minutes of observation. We analyzed the correlation between final colony size and each one of the seven censuses performed.

\section{Statistical analyses}

Most data were analyzed by applying generalized linear models (GLMs, McCullagh and Nelder 1983). When we had several measures of the same colonies in different time intervals, variance-covariance structures were modelled by using generalized linear mixed models (GLMMs), which allow us to account for nonindependence in the data set (Littell et al. 1996). We fitted the mixed models by proc MIXED in SAS when the response variable was normally distributed or could be normalized. Appropriate link functions and error structures for Poisson and binomially distributed data were implemented by using the SAS macro GLIMMIX. For all multivariable analyses, we started with a sat-

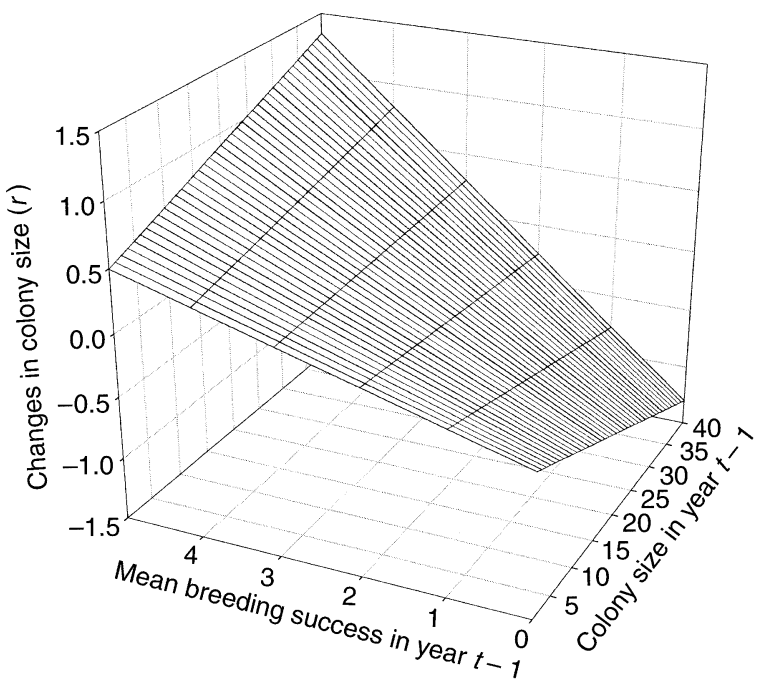

FIG. 1. Relationship between changes in colony size of Lesser Kestrels between year $t$ and $t-1(r)$ and mean breeding success in year $t-1$ in the Mid Ebro Valley, northeastern Spain. The grid was based on a mixed model (see Table 1) where the colony size effect and the colony size $\times$ mean breeding success interaction were also accounted for. urated model including the main effects and all interactions as fixed terms and colony identity and year as random terms. Model selection was made by sequentially removing nonsignificant variables starting with the interactions. Higher polynomial models were also fitted to account for potential nonlinear relationships. All tests were two-tailed.

\section{RESUlts}

The role of breeding success and dispersal status on colony dynamics

Changes in colony size were positively related to mean breeding success in year $t-1$, but this effect increased with colony size as indicated by the significant interaction between both effects (Table 1, Fig. 1). Importantly, predation rate was the main determinant of mean breeding success in the colonies (estimate \pm $1 \mathrm{SE}=-0.01260 \pm 0.000319 ; F_{1,236}=1563.18, P<$ 0.0001 ; explained deviance $=77.65 \%$ ) . Therefore, predation negatively affected colony dynamics, its effect also varying with colony size (percentage of predated nests, estimate $\pm 1 \mathrm{SE}=-0.00527 \pm 0.000638 ; F_{1,259}$ $=68.00, P<0.0001$; colony size, $-0.00082 \pm$ $0.004176 ; F_{1,259}=0.04, P=0.084$; percentage of predated nests $\times$ colony size, $-0.00033 \pm 0.000107 ; F_{1,259}$ $=9.31, P=0.0025)$.

When colony dynamics was analyzed with respect to the dispersal status of individuals breeding in year $t$, significant interactions of colony size with the number of philopatric adults, immigrant adults, and firstbreeding immigrants were detected (Table 2). This means that the contribution of individuals of each dispersal status to colony dynamics differed among colonies of different sizes. Philopatric first-breeding birds, however, had a similar effect on colony dynamics in the whole range of colony sizes (Table 2). Note, however, that all these values are intercorrelated among each other (Spearman rank correlation coefficients $r_{\mathrm{s}}=0.46-0.72$; all $P$ values $\left.<0.0001\right)$. Multicollinearity decreases statistical power and causes exclusion of significant variables (Graham 2003), problems that can be ignored in this model because all input variables were significant. Taken together, univariable analyses showed that colony dynamics was affected, in order of 
TABLE 2. Mixed model for the relationship between changes in colony size and dispersal status of individuals breeding at a colony site in year $t$.

\begin{tabular}{lcrrr}
\hline \hline \multicolumn{1}{c}{ Parameter } & Estimate & SE & $F$ & $P$ \\
\hline Intercept & -0.63420 & 0.03620 & & $<0.0001$ \\
Colony size (CS) & -0.04253 & 0.00839 & 25.71 & 0.3039 \\
Philopatric adults (PA) & 0.00996 & 0.00962 & 1.07 & $<0.0001$ \\
Immigrant adults (IA) & 0.15290 & 0.01593 & 92.11 & $<0.0001$ \\
Philopatric first-breeders (PF) & 0.06243 & 0.02369 & 70.10 & 0.0103 \\
Immigrant first-breeders (IF) & 0.15240 & 0.01821 & 6.95 & 0.0010 \\
PA × CS & 0.001083 & 0.00032 & 11.85 & 0.0002 \\
IA × CS & -0.00357 & 0.00091 & 15.35 & $<0.0001$ \\
IF × CS & -0.00718 & 0.00119 & 36.25 & \\
Explained deviance (\%) & 68.21 & & & \\
\hline
\end{tabular}

Notes: Colony size was measured in year $t-1$. Colony site and year were fitted as random terms.

importance, by adult philopatry $(52.25 \%$ of the deviance), natal immigration (48.34\%), adult immigration $(46.48 \%)$, and natal philopatry $(39.51 \%)$. The contribution that philopatric adults made to colony dynamics was very little in small colonies, but increased dramatically with colony size (Fig. 2). The contribution of immigrants (both first-breeders and adults) was important in small and medium-sized colonies, while its influence was much lower in large ones (Fig. 2). Intercorrelation among predictors, however, also could cause inaccurate model parameterization (Graham 2003), but at least sign of estimates can be obtained, and uncertainty is not likely to cause severe problems when interpreting individual coefficients of the strongest effects.

In places with only one breeding pair, immigrants were expected to have a major effect on colony growth, since the effect of the number of locally born individuals and philopatric individuals is necessarily small. However, why does immigration have only a small effect on the dynamics of large colonies? To answer this question, we investigated the absolute number of philopatric adults and immigrants at colonies of different sizes. The number of individuals of both states increased with colony size the year before, although the number of immigrants increased only up to a maximum

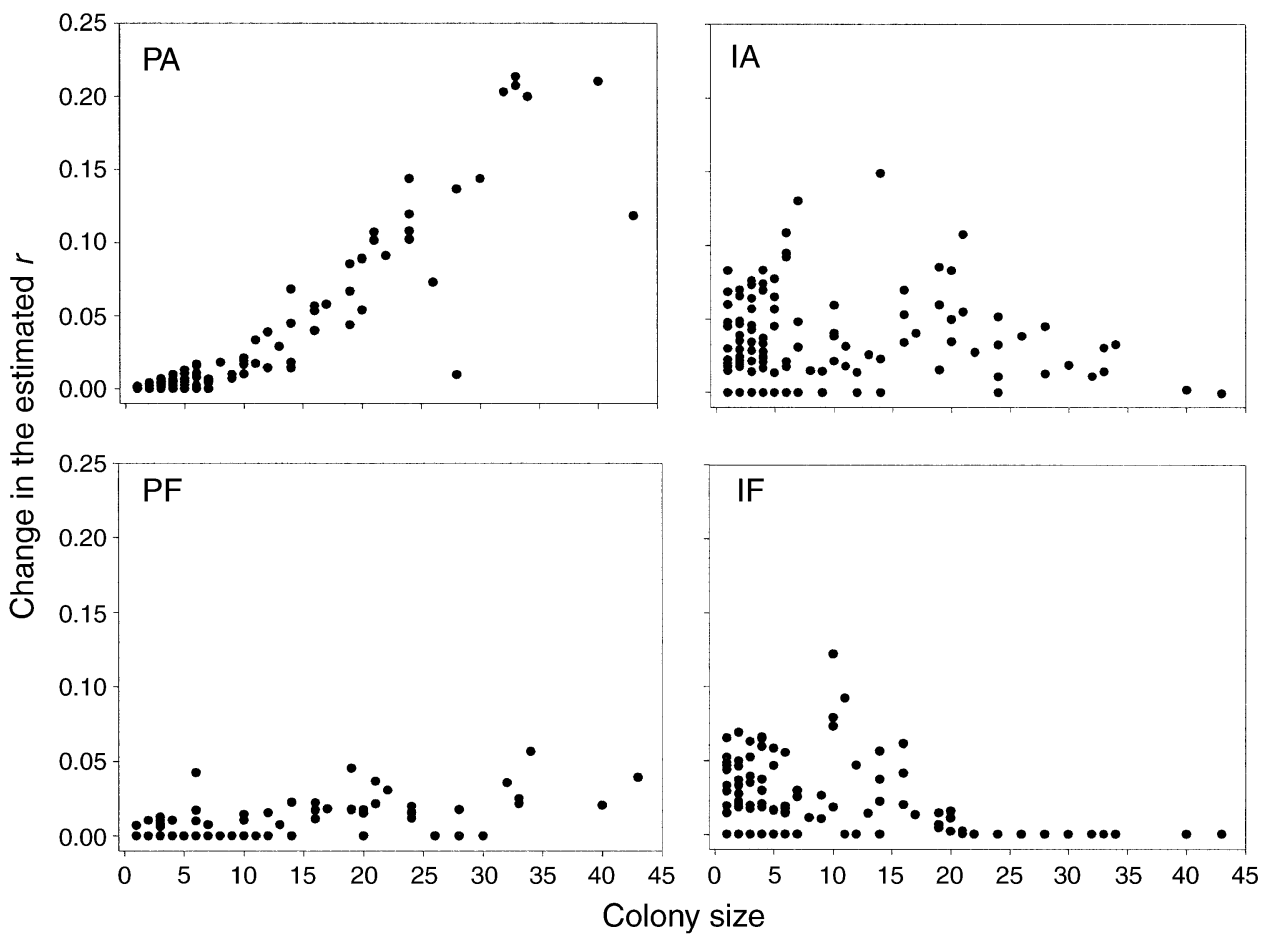

FIG. 2. Sensitivity of the mixed model of interannual changes in colony size of Lesser Kestrels $(r)$ to changes in the number of individuals of each dispersal status: philopatric adults (PA), immigrant adults (IA), philopatric first-breeders (PF), and immigrant first-breeders (IF). Senstivity in each of the input variables was assessed by increasing its observed value by $10 \%$ while all other variables were held constant and then calculating the change in the magnitude of the estimated $r$. Colony size is also shown, as the effect of most variables varies with the number of breeding pairs in year $t-1$ (see Table 2 ). 


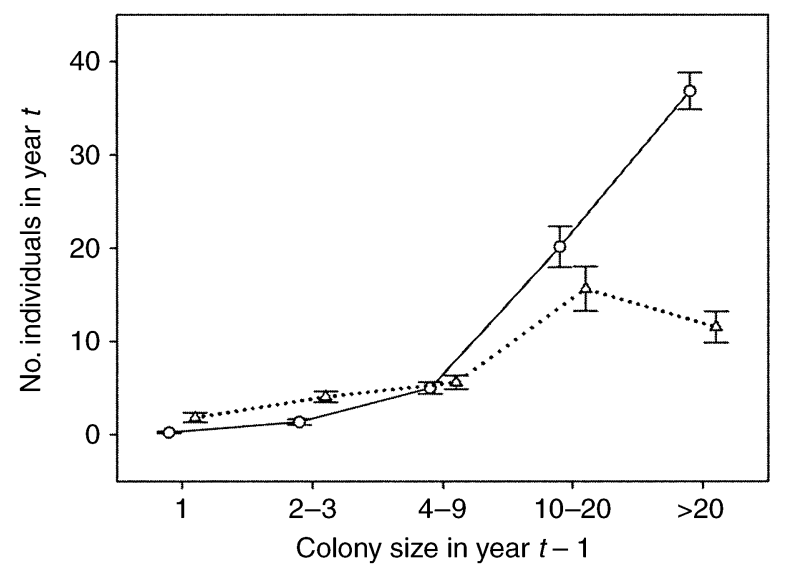

FIG. 3. Relationship between colony size of Lesser Kestrels in year $t-1$ and the estimated number of philopatric adults (circles, solid line) and immigrants (triangles, dotted line) in year $t$. Note that only colonies with $<15 \%$ of nests depredated in year $t-1$ are shown to account for the confounding effect of differential nest failure associated with colony size. Means $( \pm 1 \mathrm{SE})$ for the estimated number of individuals are represented.

in colonies of 10-20 pairs (philopatric adults, estimate $\pm 1 \mathrm{SE}=0.04658 \pm 0.003084, F_{1,77}=228.09, P<$ 0.0001 ; immigrants, $0.05414 \pm 0.005277, F_{1,77}=$ 105.24, $P<0.0001$; philopatric adults $\times$ immigrants, $-0.00220 \pm 0.000288, F_{1,77}=58.62, P<0.0001$; see Fig. 3).

\section{Relative role of performance-based and social attraction}

Assumption 1: Spatial and temporal variability in colony quality. - The number of fledglings reared per nest was analyzed according to colony site and year (colony, $\chi_{284}^{2}=960.67, P<0.0001$; year, $\chi_{7}^{2}=91.46$, $P<0.0001$; colony $\times$ year, $\chi_{447}^{2}=1062.39, P<$ 0.0001). As the interaction between both effects was significant, we analyzed breeding success for each year separately and found that it varied among colonies in all years (all $P$ values $<0.0001$ ). Thus, colony quality, in terms of breeding performance, varied both in space and time and breeding habitat selection is expected.

Assumption 2: Temporal autocorrelation in colony quality.-We investigated the relationship between mean breeding success in year $t$ and mean breeding success at various time lags to analyze temporal predictability of the environment. The environment appeared predictable from one year to the next (partial autoregressive mixed model; estimate $\pm 1 \mathrm{SE}=0.1169$ $\left.\pm 0.02984 ; F_{1,118}=15.35, P=0.0001\right)$, but not for time lags of two years $\left(F_{1,118}=0.46, P=0.498\right)$ or more.

Assumption 3: Predictability of final colony size early in the breeding season.-Final colony size was positively and highly correlated with the number of individuals in each of the seven censuses performed $(F$ values, 51.70-171.61; df, 1, 24; all $P$ values $<0.0001$ ).
Thus, birds prospecting early in the season could predict final colony size even if they attended the colonies only during short time periods.

Conspecific cues and colony selection.-Given that the assumptions of both hypotheses were met, we tested whether nonlocal recruits cue on the number of conspecifics and/or on public information to select their breeding site. We analyzed whether the number of nonlocal birds that had opportunity of prospecting at each colony, i.e., immigrating adults and immigrating 2-yr individuals, was associated with the number of philopatric adults in year $t$ and/or with the mean breeding success in year $t-1$. We first tested both effects univariately and found that the number of nonlocal recruits was positively related to the number of philopatric adults (estimate $\pm 1 \mathrm{SE}=0.03616 \pm 0.005836 ; F_{1,53}$ $=38.39, P<0.0001$ ), but not to the mean breeding success of conspecifics $\left(F_{1,49}=2.28, P=0.1376\right.$; see Fig. 4). When both effects were tested simultaneously in a mixed model the results showed the same pattern (philopatric adults, $F_{1,48}=34.72, P<0.0001$; mean breeding success, $F_{1,48}=1.99, P=0.1643$ ). Both effects were correlated (Spearman rank correlation coefficient, $r_{\mathrm{S}}=0.388, P<0.0001$ ), and as even low levels of collinearity have been shown to potentially bias regression analyses (Graham 2003), we performed a complementary analysis to reinforce these results. Given that random terms were not significant in the multivariable mixed model (colony, $Z=0.67, P=$ 0.2512 ; year, $Z=1.24, P=0.1076$ ), we used a GLM with a type I approach, first regressing one effect against the dependent variable and then testing the residuals against the other. We did this analysis twice, changing the order of fitting the effects in the process, and once again we only found support to the social attraction hypothesis (philopatric adults fitted first, $F_{1,109}=49.02, P<0.0001 ;$ philopatric adults fitted second, $F_{1,109}=48.64, P<0.0001$; mean breeding

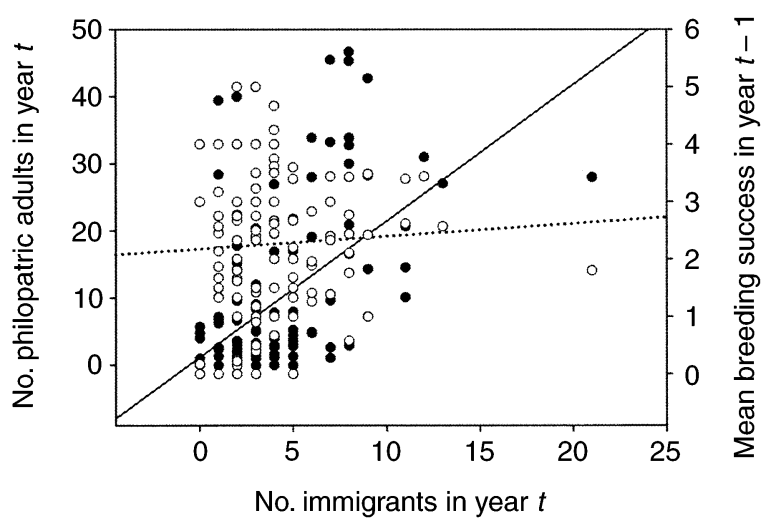

FIG. 4. Relationship between the number of immigrant Lesser Kestrels that had opportunity to prospect with the number of philopatric adults in year $t$ (solid circles, solid line) and the mean breeding success in year $t-1$ (open circles, dotted line). 
success fitted first, $F_{1,109}=1.66, P=0.1982$; mean breeding success fitted second, $F_{1,109}=1.27, P=$ $0.2591)$. Since there was a colony-year that could be influencing our results (see the colony that had more than 20 immigrants in Fig. 4), we repeated all these analyses removing this point, but the results were nearly identical.

\section{DISCUSSION}

Inter-year changes in colony size of Lesser Kestrels were affected by breeding success, which is mainly related to predation pressure, as has been shown in other colonial birds (e.g., Southern et al. 1985, Kilpi 1995). However, few studies have attempted to quantify how colony quality influences settlement and departure decisions to regulate colony dynamics (e.g., Danchin and Monnat 1992, Brown et al. 2000, Oro and Ruxton 2001). In Lesser Kestrels, individuals of all dispersal status contributed to colony dynamics, although the relative importance of immigrants and philopatric adults varied with colony size. Importantly, natal philopatry was the less influential parameter, which indicates that the effect of breeding success on colony dynamics is not trivially explained by the recruitment of locally born individuals, but reflects an important effect of colony quality on dispersal performance and breeding site selection.

As expected, immigration is the main factor affecting changes in the size of small colonies. In contrast, the number of philopatric adults was responsible for the strongest temporal variations in the size of largest colonies. This result could arise from the fact that large colonies can eventually experience massive adult dispersal events associated with total breeding failure because of predation (Serrano et al. 2001a), but never experience immigration rates of the same magnitude. Consistently, the number of immigrants increased with colony size up to a threshold (Fig. 3), but above this threshold external recruitment showed a downward trend that may be explained by density-dependent mechanisms to prevent immigrants from joining. This would arise from the greater familiarity with the nesting sites and competing neighbors of previous residents (Krebs 1982, Jakobsson 1988, Tobias 1997). In this scenario, philopatric adults would have the greatest interest in residence and would be behaviorally dominant over newcomers, preventing them from settling in a despotic way (Brown et al. 1990). In Lesser Kestrels, an increase in colony size reduces the mean nearest neighbor distance and increases dramatically the agonistic interactions among individuals (Tella 1996, Negro et al. 1997, Serrano et al. 2003). Indeed, individuals in large colonies have a markedly lower body condition than in small colonies when breeding sites are being established (Tella 1996), suggesting that individuals have to pay significant costs to defend a nest site in a large colony. Negative density-dependent immigration explains the decreasing importance of immigrants on colony dynamics as colony size increases, as well as the equilibrium population size attained in the largest colonies in absence of high predation pressure.

\section{The role of conspecific cues on colony dynamics}

Danchin et al. (2001) and Doligez et al. (2003) questioned the literature supporting the conspecifc attraction hypothesis, arguing that social attraction might have been confounded with performance-based attraction. Our study tried to separate the predictions of both hypotheses and supported the idea that social attraction is more important than performance-based attraction for colony selection in Lesser Kestrels. This result is intriguing, as patch quality is temporally autocorrelated, and thereby a strategy based on public information is theoretically expected to perform better than social attraction (Doligez et al. 2003). However, the availability of this information and/or the costs of gathering it could have precluded the evolution of performancebased strategies (Boulinier and Danchin 1997, Doligez et al. 2004). For example, Lesser Kestrels are holenesting birds, and therefore individuals may find it difficult to gather extensive information about reproductive success of others. Furthermore, Lesser Kestrel fledglings stay in the breeding colonies only a few days (Bustamante and Negro 1994), so there could be serious time constraints in the acquisition of this information (Boulinier et al. 1996, Reed et al. 1999). We have shown, however, that colony size is easy to assess (i.e., a few minutes per colony) during a substantially longer time period (i.e., 2.5 mo from arrival to laying date).

Habitat selection based on the decisions of other individuals could be less efficient than a strategy based directly on the outcome of conspecific reproduction, because the performance of this strategy is strongly affected by the ability of already-present individuals to settle in good-quality patches (Beauchamp et al. 1997). So, individuals imitating incorrect behavioral decisions could fall into erroneous informational cascades (Giraldeu et al. 2002). However, prospecting kestrels may reliably use the number of conspecifics to select where to settle because departure decisions of established breeders are based on personal information about breeding success (Serrano et al. 2001a), and the increase in mean lifetime reproductive success with colony size shows a net advantage of coloniality in this species (Tella 1996). Furthermore, individuals can easily estimate final colony size, and thus their "optimal" colony size for breeding, when returning from the wintering quarters. By cueing on the number of conspecifics, the time and energy costs of direct habitat assessment are probably relaxed, especially in migratory birds such as the Lesser Kestrel. Moreover, this strategy of habitat selection may be beneficial because the main determinant of breeding success is nest predation by nocturnal mammals (Tella 1996), which are unlikely to be detected by the kestrels when settling in the colonies. 
Shields et al. (1988) proposed that Barn Swallows (Hirundo rustica) used the number of nests remaining from the previous breeding season to assess colony quality and the probability of breeding successfully. This "traditional aggregation hypothesis" would explain why birds accumulated at successful sites, finally conducting to perennially large colonies. The main predators of Lesser Kestrels, red foxes and brown rats, are nocturnal mammals that cannot be deterred by the kestrels (Tella 1996). Thus, low predation events in large colonies are not a consequence of effective predator mobbing, but large colonies persist in buildings inaccessible to predators (Tella 1996). The number of conspecifics is thereby a good indicator of breeding patch quality, and the logic of colony selection and growth in this species appears to be similar to that described by Shields et al. (1988) in the sense that birds could use the number of established conspecifics as an index of "historic security" of the breeding site. To the extent that this mechanism implies the judgment of the relative profitability of the breeding colony on the basis of the decisions of other individuals, and that these decisions provide reliable information about current local environmental quality, social attraction in Lesser Kestrels could be interpreted as habitat copying (Wagner and Danchin 2003) and could even be seen as a particular case of a source of public information. As reported in a foraging context (Valone and Giraldeu 1993, Smith et al. 2001, Coolen et al. 2003), our findings suggest that the use of mean breeding success of conspecifics to select the breeding patch could be widespread in some species but not in others, and the use of other strategies such as social attraction could depend on life history traits and ecological determinants (Tella et al. 1998b). Particularly, social attraction is expected to predominate when individuals have access to information about behavioral decisions of conspecifics, but have limited access to the cue on which those decisions were based.

Taken together, our results present a picture of colony dynamics in Lesser Kestrels. Colonies are usually founded by a low number of birds (Tella 1996). Pioneering individuals cannot assess habitat quality through conspecifics, so they are expected to select a site on the basis of direct habitat assessment or on the presence of heterospecifics (Monkkonen et al. 1999). If they experience breeding failure, they tend to disperse to other colonies (Serrano et al. 2001a), and such a site is unlikely to attract immigrants. In contrast, adults in successful sites have a higher probability of returning to the same colony to breed and act as attractors to immigrants (Serrano et al. 2001a). The extent of colony growth in these successful colonies would be affected by the number of immigrants, which would in turn be determined by the spatial distribution, size, and breeding success of the neighboring colonies (Serrano et al. 2001a, 2003). If the colony site continues being a safe place in subsequent years, the number of individuals increases from year to year through immigrants joining the philopatric adults, until colony size reaches a point at which immigrants are prevented from joining or is otherwise disadvantageous in terms of settlement costs. Thus, large colonies reflect a benign environment for breeding, although conspecifics seem to produce opposing effects in the largest colonies probably by attracting, but also by preventing, potential immigrants from settling. In our population, many individuals seem to have low chances of joining a large colony, so settling in a small colony or even pioneering an unoccupied building may become "the best of a bad job" for some individuals in spite of the risk of breeding failure (Forbes and Kaiser 1994). This model, together with the instability of colony quality between time lags of more than two years, could explain spatiotemporal variations in colony size and why all individuals do not concentrate in a few big colonies (Brown and Rannala 1995).

In conclusion, our findings emphasize the importance of positive as well as negative effects of conspecifics on habitat selection processes (Stamps 2001). Social attraction allows dispersers to locate suitable breeding sites quickly and to obtain fitness benefits after settling, but they seem to be faced with settlement costs in the largest colonies. The singularity of our results is that they could explain spatiotemporal variations in colony size, as well as the behavioral mechanisms maintaining facultative coloniality in this and probably other species of colonial birds. Nonetheless, colony choice is a complex behavior that may include private and public information, social attraction, and direct habitat assessment. The costs and benefits of obtaining these types of information seem to differ among species, so more detailed studies on both colonial and territorial birds with different life history traits are needed.

\section{ACKNOWLEDGMENTS}

We are indebted to E. Ursúa, A. Gajón, R. López, O. Ceballos, Y. Menor, F. Hiraldo, A. Giráldez, J. M. Grande, I. Luque, R. Jovani, L. Bolonio, F. J. Moreno, E. Pelayo, F. J. Sampietro, I. Sánchez, I. Bisson, G. Blanco, M. Bertellotti, C. Sánchez, M. Pomarol, E. Muñoz, M. Villarroel, J. C. Cirera, F. Hernández, C. Cortázar, J. Blasco, and J. A. Pinzolas for helping us to monitor the colonies. Daniel Oro, Etienne Danchin, Roger Jovani, and two anonymous reviewers offered important suggestions to early drafts. During writing M. G. Forero was supported by a contract Ramón y Cajal of de MCyT of Spain. Financial support was partially provided by collaborative projects with Diputación General de Aragón (1994-95 and 2000), SEO/BirdLife (1998-99), and by DGICYT and DGES Projects PB93-0040 and PB96-0834.

\section{Literature Cited}

Alexander, R. D. 1974. The evolution of social behavior. Annual Review of Ecology and Systematics 5:325-383.

Beauchamp, G., M. Bélisle, and L.-A. Giraldeu. 1997. Influence of conspecific attraction on the spatial distribution of learning foragers in a patchy habitat. Journal of Animal Ecology 66:671-682. 
Booth, D. J. 1992. Larval settlement patterns and preferences by domino damselfish Dascyllus albisella Gill. Journal of Experimental Marine Biology and Ecology 155:85-104.

Boulinier, T., and E. Danchin. 1997. The use of conspecific reproductive success for breeding patch selection in territorial migratory species. Evolutionary Ecology 11:505517.

Boulinier, T., E. Danchin, J.-Y. Monnat, C. Doutrelant, and B. Cadiou. 1996. Timing of prospecting and the value of information in a colonial breeding bird. Journal of Avian Biology 27:252-256.

Boulinier, T., N. G. Yoccoz, K. D. McCoy, K. E. Erikstad, and T. Tveraa. 2002. Testing the effect of conspecific reproductive success on dispersal and recruitment decisions in a colonial bird: design issues. Journal of Applied Statistics 29:509-520.

Brown, C. R., and M. B. Brown. 1986. Ectoparasitism as a cost of coloniality in Cliff Swallows (Hirundo pyrrhonota). Ecology 67:1206-1218.

Brown, C. R., and M. B. Brown. 1996. Coloniality in the cliff swallow. Chicago University Press, Chicago, Illinois, USA.

Brown, C. R., and M. B. Brown. 2001. Avian coloniality: progress and problems. Current Ornithology 16:1-82.

Brown, C. R., M. B. Brown, and E. Danchin. 2000. Breeding habitat selection in cliff swallows: the effect of conspecific reproductive success on colony choice. Journal of Animal Ecology 69:133-142.

Brown, C. R., and B. Rannala. 1995. Colony choice in birds: models based on temporally invariant site quality. Behavioral Ecology and Sociobiology 36:221-228.

Brown, C. R., B. J. Stutchbury, and P. D. Walsh. 1990. Choice of colony size in birds. Trends in Ecology and Evolution 5:398-407.

Bustamante, J., and J. J. Negro. 1994. The post-fledging dependence period of the lesser kestrel (Falco naumanni) in southwestern Spain. Journal of Raptor Research 28:158163.

Clobert, J., E. Danchin, A. Dhondt, and J. D. Nichols. 2001. Dispersal. Oxford University Press, Oxford, UK.

Cody, M. L. 1985. Habitat selection in birds. Academic Press, San Diego, California, USA.

Coolen, I., Y. van Bergen, R. L. Day, and K. N. Laland. 2003. Species difference in adaptive use of public information in sticklebacks. Proceedings of the Royal Society of London B 270:2413-2419.

Danchin, E., T. Boulinier, and M. Massot. 1998. Conspecific reproductive success and breeding habitat selection: implications for the study of coloniality. Ecology 79:24152428.

Danchin, E., D. Heg, and B. Doligez. 2001. Public information and breeding habitat selection. Pages 243-258 in J. Clobert, E. Danchin, A. A. Dhondt, and J. D. Nichols, editors. Dispersal. Oxford University Press, Oxford, UK.

Danchin, E., and J.-Y. Monnat. 1992. Population dynamics modelling of two neighbouring kittiwake Rissa tridactyla colonies. Ardea 80:171-180.

Danchin, E., and R. H. Wagner. 1997. The evolution of coloniality: the emergence of new perspectives. Trends in Ecology and Evolution 12:342-347.

Doligez, B., C. Cadet, E. Danchin, and T. Boulinier. 2003. When to use public information for breeding habitat selection? The role of environmental predictability and density dependence. Animal Behaviour 66:973-988.

Doligez, B., E. Danchin, and J. Clobert. 2002. Public information and breeding habitat selection in a wild bird population. Science 297:1168-1170.

Doligez, B., T. Pärt, E. Danchin, J. Clobert, and L. Gustafsson. 2004. Availability and use of public information and con- specific density for settlement decisions in the collared flycatcher. Journal of Animal Ecology 73:75-87.

Duffy, D. C. 1983. The ecology of tick parasitism on densely nesting Peruvian seabirds. Ecology 64:110-119.

Etterson, M. A. 2003. Conspecific attraction in loggerhead shrikes: implications for habitat conservation and reintroduction. Biological Conservation 114:199-205.

Forbes, L. S., M. Jajam, and G. W. Kaiser. 2000. Habitat constraints and spatial bias in seabird colony distributions. Ecography 23:575-578.

Forbes, L. S., and G. W. Kaiser. 1994. Habitat choice in breeding seabirds: when to cross the information barrier. Oikos 70:377-384.

Forero, M. G., J. L. Tella, J. A. Donázar, and F. Hiraldo. 1996. Can interspecific competition and nest site availability explain the decrease of lesser kestrel Falco naumanni population? Biological Conservation 78:289-293.

Forero, M. G., J. L. Tella, K. A. Hobson, M. Bertellotti, and G. Blanco. 2002. Conspecific food competition explains variability in colony size: a test in Magellanic Penguins. Ecology 83:3466-3475.

Furness, R. W., and T. R. Birkhead. 1984. Seabird colony distributions suggest competition for food supplies during the breeding season. Nature 311:655-656.

Giraldeu, L.-A., T. J. Valone, and J. J. Templeton. 2002. Potential disadvantages of using socially acquired information. Philosophical Transactions of the Royal Society of London B 357:1559-1566.

Graham, M. H. 2003. Confronting multicollinearity in ecological multiple regression. Ecology 84:2809-2815.

Hoeck, H. N. 1989. Demography and competition in hyrax: a 17 years study. Oecologia 79:353-360.

Jakobsson, S. 1988. Territorial fidelity of willow warbler (Phylloscopus trochilus) males and success in competition over resource. Behavioral Ecology and Sociobiology 22: 79-84.

Jeffries, D. S., and D. H. Brunton. 2001. Attracting endangered species to 'safe' habitats: responses of Fairy Terns to decoys. Animal Conservation 4:301-305.

Kharitonov, S. P., and D. Siegel-Causey. 1990. Colony formation in seabirds. Current Ornithology 5:223-271.

Kilpi, M. 1995. Breeding success, predation and local dynamics of colonial Common Gulls Larus canus. Annales Zoologici Fennici 32:175-182.

Kotliar, N. B., and J. Burguer. 1984. The use of decoys to attract Least Terns (Sterna antillarum) to abandoned colony sites in New Jersey. Colonial Waterbirds 7:134-138.

Krebs, J. R. 1982. Territorial defence in the Great Tit, Parus major: do residents always win? Behavioral Ecology and Sociobiology 11:185-194.

Kress, S. W., and D. N. Nettleship. 1988. Re-establishment of Atlantic puffins (Fratercula arctica) at a former breeding site in the Gulf of Maine. Journal of Field Ornithology 59: 161-170.

Littell, R. C., G. A. Milliken, W. W. Stroup, and R. S. Wolfinger. 1996. SAS system for mixed models. SAS Institute, Cary, North Carolina, USA.

McCullagh, P., and J. A. Nelder. 1983. Generalised linear modelling. Chapman and Hall, London, UK.

Monkkonen, M., R. Hardling, J. T. Forsman, and J. Tuomi. 1999. Evolution of heterospecific attraction: using other species as cues in habitat selection. Evolutionary Ecology 13:91-104.

Muller, K. L. 1998. The role of conspecifics in habitat settlement in a territorial grasshopper. Animal Behaviour 56: 479-485.

Muller, K. L., J. A. Stamps, V. V. Krishnan, and N. H. Willits. 1997. The effects of conspecific attraction and habitat quality on habitat selection in territorial birds (Troglodytes aedon). American Naturalist 150:650-661. 
Negro, J. J., F. Hiraldo, and J. A. Donázar. 1997. Causes of natal dispersal in the lesser kestrel: inbreeding avoidance or resource competition? Journal of Animal Ecology 66: 640-648.

Nur, N., and W. J. Sydeman. 1999. Demographic processes and population dynamic models of seabirds. Current Ornithology 15:149-188.

Orians, G. H., and J. F. Wittenberger. 1991. Spatial and temporal scales in habitat selection. American Naturalist 137: S29-S49.

Oro, D., E. Cam, R. Pradel, and A. Martínez-Abraín. 2003. Influence of food availability on demography and local population dynamics in a long-lived seabird. Proceedings of the Royal Society of London B 271:387-396.

Oro, D., and G. D. Ruxton. 2001. The formation and growth of seabird colonies: Audouin's gull as a case study. Journal of Animal Ecology 70:527-535.

Pawlik, J. R. 1992. Chemical ecology of the settlement of benthic marine invertebrates. Oceanography and Marine Biology 30:273-335.

Podolsky, R. H. 1990. Effectiveness of social stimuli in attracting Laysan albatross to new potential nesting sites Auk 107:119-125.

Potts, G. R., J. C. Coulson, and I. R. Deans. 1980. Populations dynamics and the breeding success of the Shag Phalacrocorax aristotelis, on the Farne Islands, Northumberland. Journal of Animal Ecology 49:465-484.

Reed, J. M., T. Boulinier, E. Danchin, and L. W. Oring. 1999. Informed dispersal: prospecting by birds for breeding sites. Current Ornithology 15:189-259.

Reed, J. M., and A. P. Dobson. 1993. Behavioural constraints and conservation biology: conspecific attraction and recruitment. Trends in Ecology and Evolution 8:253-256.

Rolland, C., E. Danchin, and M. de Fraipont. 1998. The evolution of coloniality in birds in relation to food, habitat, predation, and life-history traits: a comparative analysis. American Naturalist 151:514-529.

Sarrazin, F., C. Bagnolini, J. L. Pinna, and E. Danchin. 1996. Breeding biology during establishment of a reintroduced griffon vulture Gyps fulvus population. Ibis 138:315-325.

Serrano, D., and J. L. Tella. 2003. Dispersal within a spatially structured population of lesser kestrels: the role of spatial isolation and conspecific attraction. Journal of Animal Ecology 72:400-410.

Serrano, D., J. L. Tella, J. A. Donázar, and M. Pomarol. 2003. Social and individual features affecting natal dispersal in the colonial Lesser Kestrel. Ecology 84:3044-3054.

Serrano, D., J. L. Tella, M. G. Forero, and J. A. Donázar 2001a. Factors affecting breeding dispersal in the facultatively colonial lesser kestrel: individual experience vs. conspecific cues. Journal of Animal Ecology 70:568-578.

Serrano, D., E. Ursúa, A. Gajón, and J. L. Tella. 2001b. Conservation status and breeding avian species in farmhouses located in the ZEPAs of Los Monegros. Final Project Report. Wildlife Service, Government of Aragón, Zaragoza, Spain.
Shields, W. M., J. R. Crook, M. L. Hebblethwaite, and S. S. Wiles-Ehmann. 1988. Ideal free coloniality in swallows. Pages 189-228 in C. N. Slobodchikoff, editor. The ecology of social behavior. Academic Press, San Diego, California, USA.

Smith, R. D., G. D. Ruxton, and W. Cresswell. 2001. Patch choice decisions on wild blackbirds: the role of preharvest public information. Animal Behaviour 61:1113-1124.

Southern, W. E., S. R. Patton, L. K. Southern, and L. A. Hanners. 1985. Effects of nine years of fox predation on two species of breeding gulls. Auk 102:827-833.

Stamps, J. A. 1988. Conspecific attraction and aggregation in territorial species. American Naturalist 131:329-347.

Stamps, J. A. 2001. Habitat selection by dispersers: integrating proximate and ultimate approaches. Pages 230-242 in J. Clobert, E. Danchin, A. A. Dhondt, and J. D. Nichols, editors. Dispersal. Oxford University Press, Oxford, UK.

Tella, J. L. 1996. Ecological constraints, costs and benefits of coloniality in the lesser kestrel. Dissertation. University of Barcelona, Barcelona, Spain.

Tella, J. L., M. Carrete, J. A. Sánchez-Zapata, D. Serrano, A. Gavrilov, S. Sklyarenko, O. Ceballos, J. A. Donázar, and F. Hiraldo. 2004. Effects of land use, nesting-site availability, and the presence of larger raptors on the abundance of vulnerable lesser kestrels in Kazakhstan. Oryx 38:224227.

Tella, J. L., and M. G. Forero. 2000. Farmland habitat selection of wintering lesser kestrels in a Spanish pseudosteppe: implications for conservation strategies. Biodiversity and Conservation 9:433-441.

Tella, J. L., M. G. Forero, F. Hiraldo, and J. A. Donázar. 1998a. Conflicts between lesser kestrel conservation and European agricultural policies as identified by habitat use analysis. Conservation Biology 12:593-604.

Tella, J. L., F. Hiraldo, and J. A. Donázar. 1998b. The evolution of coloniality: does commodity selection explain it all? Trends in Ecology and Evolution 13:75-76.

Tobias, J. 1997. Asymmetric territorial contests in the European robin: the role of settlement costs. Animal Behaviour 54:9-21.

Valone, T. J. 1989. Group foraging, public information, and patch estimation. Oikos 56:357-363.

Valone, T. J., and L.-A. Giraldeu. 1993. Patch estimation by group foragers: what information is used? Animal Behaviour 45:721-728.

Valone, T. J., and J. J. Templeton. 2002. Public information for the assessment of quality: a widespread social phenomenon. Philosophical Transactions of the Royal Society of London B 357:1549-1557.

Wagner, R. H., and E. Danchin. 2003. Conspecific copying: a general mechanism of social aggregation. Animal Behaviour 65:405-408.

Ward, M. P., and S. Schlossberg. 2004. Conspecific attraction and the conservation of territorial songbirds. Conservation Biology 18:519-525.

Wittenberger, J. F., and G. L. Hunt. 1985. The adaptive significance of coloniality in birds. Pages $1-78$ in D. S. Farner and J. R. King, editors. Avian biology. Volume 8. Academic Press, San Diego, California, USA. 